\title{
Chức năng của Viện kiểm sát nhân dân trong giải quyết tố giác, tin báo tội phạm, kiến nghị khởi tố theo Bộ luật tố tụng hình sự năm 2015 và một số kiến nghị hoàn thiện
}

\author{
Trần Thu Hạnh", Ngô Long Khánh \\ Khoa Luật, ĐHQGHN, 144 Xuân Thủy, Cầu Giấy, Hà Nội, Việt Nam \\ Nhận ngày 16 tháng 8 năm 2017 \\ Chỉnh sửa ngày 09 tháng 9 năm 2017; Chấp nhận đăng ngày 25 tháng 9 năm 2017
}

\begin{abstract}
Tóm tắt: Trong bối cảnh Bộ luật Tố tụng hình sự (BLTTHS) 2015 đã được ban hành nhưng chưa có hiệu lực, nhóm tác giả nghiên cứu một số quy định về chức năng của Viện kiểm sát nhân dân trong giải quyết tố giác, tin báo tội phạm, kiến nghị khởi tố và đưa ra kiến nghị hoàn thiện các quy định này trong BLTTHS 2015.
\end{abstract}

Tư khóa: Quyền công tố, kiểm sát việc tuân theo pháp luật, giải quyết tin báo, tố giác tội phạm và kiến nghị khởi tố, bộ luật tố tụng hình sự 2015.

Theo quy định của BLTTHS 2003, thực hành quyền công tố và kiểm sát việc tuân theo pháp luật là hai chức năng của Viện kiểm sát. Tiếp tục thống nhất quan điểm này, BLTTHS 2015 nêu rõ tại Điều 20: "Viện kiểm sát thưc hành quyền công tố và kiểm sát viẹc tuân theo pháp luật trong tố tụng hình sư, quyết định việc buộc tội, phát hiện vi phạm pháp luật nhằm bảo đảm moi hành vi phạm tội, ngươi phạm tọi, pháp nhân phạm tội, vi phạm pháp luật đều phải được phát hiện và xủ lý kịp thời, nghiêm minh...”. Tuy nhiên, về những quy định cụ thể, giữa hai bộ luật có sự khác biệt. Nổi bật là những nội dung về chức năng của Viện kiểm sát nhân dân (VKSND) trong việc giải quyết tố giác, tin báo tội phạm, kiến nghị khởi tố. Trong bối cảnh Việt Nam đang xây dựng nhà nước pháp quyền xã hội chủ nghĩa, VKSND lại là

\footnotetext{
*Tác giả liên hệ. ĐT.: 84-24-37547512.

Email: tranthuhanh72@yahoo.com

https://doi.org/10.25073/2588-1167/vnuls.4110
}

chế định được ghi nhận tại Hiến pháp 2013, mọi sự thay đổi đều phải được nghiên cứu một cách nghiêm túc, toàn diện. Trong phạm vi bài viết, nhóm tác giả làm sáng tỏ quy định của BLTTHS 2015 về chức năng thực hành quyền công tố và kiểm sát việc tuân theo pháp luật của VKSND trong giải quyết tố giác, tin báo tội phạm, kiến nghị khởi tố và đưa ra một số kiến nghị hoàn thiện các quy định này.

\section{Chức năng thực hành quyền công tố trong giải quyết tố giác, tin báo tội phạm và kiến nghị khởi tố}

Nếu như trong BLTTHS 2003, thực hành quyền công tố là quyết định việc truy tố người phạm tội (Điều 23, khoản 1, BLTTHS 2003) thì theo BLTTHS 2015, đó là quyết định việc buộc tội (Điều 20 BLTTHS 2015). Thời điểm bắt đầu thực hành quyền công tố trong BLTTHS 2015 là từ lúc "giải quyết nguồn tin về tội phạm" 
(Điều 159) sớm hơn luật hiện hành, từ khi "khởi tố vu án" (Điều 109, BLTTHS 2003). Dường như ở BLTTHS 2015, khái niệm thực hành quyền công tố được "mở rộng" hơn và việc giải quyết tin báo, tố giác tội phạm và kiến nghị khởi tố có cùng tính chất với quyết định buộc tội. Nhưng giống như BLTTHS 2003, BLTTHS 2015 cũng chưa giải thích cụ thể quyền công tố nên lý luận của những thay đổi chưa được làm rõ. Tìm hiểu về quyền công tố là mấu chốt để hiểu đúng những điểm mới nói trên. Nghiên cứu về quyền công tố, chúng tôi tiếp cận ở những bình diện sau: đối tượng, chủ thể, nội dung và phạm vi thời gian thực hiện quyền.

Về đối tượng của quyền công tố, đa số các nhà khoa học thống nhất là tội phạm và người phạm tội. Và như thế, công tố chỉ tồn tại trong tố tụng hình sự. Dưới góc độ quyền, chỉ trong lĩnh vực hình sự, trách nhiệm pháp lý mới nghiêm khắc tới mức có thể tước bỏ những quyền cơ bản nhất của một thể nhân hay pháp nhân. Nếu sự cáo buộc trách nhiệm hình sự thuộc về tư nhân, hai thái cực khác nhau có thể xảy ra: hoặc người buộc tội không đủ mạnh nên họ không thể buộc tội hay buộc tội không chính xác. Hoặc họ quá mạnh, không được kiểm soát chặt chẽ nên xâm hại bất công đến quyền của người bị buộc tội. Khi quyền công tố được thực hiện bởi Nhà nước, nhu cầu lập lại công lý và bảo vệ quyền của người bị buộc tội mới được cân bằng. Ở các lĩnh vực luật khác không tồn tại đặc điểm này. Vì vậy, đối tượng của quyền công tố chỉ bao gồm tội phạm và người phạm tội.

Về chủ thể, duy nhất Viện kiểm sát được thực hành quyền công tố. Trách nhiệm hình sự là trách nhiệm pháp lý nghiêm khắc nhất nên chỉ cần một chủ thể buộc tội mà thôi. Nếu quyền công tố được trao cho nhiều cơ quan thì không những gây chồng chéo thẩm quyền mà khả năng xâm phạm quyền của người bị buộc tội cũng cao hơn.

Về nội dung, vấn đề được các nhà khoa học tranh luận hiện nay là: quyền công tố chỉ gồm truy tố bị can, buộc tội bị cáo trước tòa hay bao hàm cả những hoạt động trước truy tố. Giải quyết vấn đề này cần dựa trên bản chất của quyền. Vì công tố là buộc tội nên tính chất buộc tội phải được thể hiện trong mọi dạng hoạt động công tố. Nếu một hoạt động chỉ tạo điều kiện trực tiếp cho buộc tội vẫn được coi là công tố thì rất khó lý giải quan hệ giữa công tố và xét xử, xét xử và thi hành án. Buộc tội là "ghép cho ai môt việc bị luật hình sư trùng phạt" [1]. Nói cách khác, đó là sự khẳng định một người đã thực hiện tội phạm. Mà với nguyên tắc " $C O$ " quan công quyền chỉ được làm nhũng gì pháp luật cho phép", bất kỳ khẳng định nào từ cơ quan tiến hành tố tụng đều phải có cơ sở chứng minh. Theo cách tiếp cận này thì nội dung của quyền công tố chỉ bao gồm truy tố và buộc tội trước Tòa. Các hoạt động trước đó như tiếp nhận, giải quyết tố giác, tin báo tội phạm, kiến nghị khởi tố; điều tra đều nhằm mục đích tìm hiểu dấu hiệu tội phạm, chứng cứ chứng minh tội phạm, người phạm tội và những vấn đề khác liên quan đến vụ án. Kết quả của những hoạt động này là chứng minh được (thể hiện qua bản kết luận điều tra đề nghị truy tố, bản cáo trạng) hoặc không chứng minh được bị can đã thực hiện tội phạm (thể hiện bằng quyết định đình chỉ điều tra). Vì vậy, những hoạt động này chưa thể coi là nội dung của quyền công tố.

Về phạm vi thời gian thực hiện quyền, quyền công tố bắt đầu từ lúc tội phạm được thực hiện và kết thúc khi bản án của Tòa có hiệu lực pháp luật. Nhận định về thời điểm kết thúc quyền công tố dường như không còn gây tranh cãi, nhưng thời điểm bắt đầu vẫn tồn tại những ý kiến trái chiều. Về nguyên tắc, căn cứ phát sinh quyền và nghĩa vụ là sự kiện pháp lý. Đối tượng của quyền công tố là tội phạm và người phạm tội nên sự kiện phát sinh quyền công tố là tội phạm xảy ra. Tuy nhiên, thời điểm thực hành quyền công tố diễn ra khi VKSND ra bản cáo trạng để truy tố bị can. Thời điểm này dựa trên quan niệm về nội dung quyền công tố đã phân tích. Ở đây, chúng ta thấy thời điểm phát sinh không trùng với thời điểm thực hiện quyền công tố. Nguyên nhân của hiện tượng này nằm ở đặc thù: đa phần các tội phạm không được phát hiện ngay khi thực hiện (tội phạm ẩn) nên VKSND không biết và không thực hiện được quyền công tố. Dù cho cơ quan tiến hành tố tụng phát hiện được thì tính 
chất nghiêm trọng của trách nhiệm hình sự cũng yêu cầu một quá trình chứng minh lâu dài và phức tạp. So sánh với các ngành luật khác, hiện tượng thời điểm phát sinh và thời điểm thực hiện quyền không trùng nhau không phải hy hữu, có thể chứng kiến sự tương tự trong quy định về quyền kết hôn theo luật hôn nhân và gia đình 2014, quy định về nghĩa vụ quân sự theo luật nghĩa vụ quân sự 2015...

Với những phân tích nêu trên, chúng tôi cho rằng VKSND không thực hành quyền công tố trong việc giải quyết tố giác, tin báo tội phạm và kiến nghị khởi tố. Nhiệm vụ của VKSND ở những hoạt động này, thực chất, nhằm bước đầu làm rõ nghi vấn về tội phạm và người phạm tội. Sự nghi vấn tồn tại khi căn cứ chứng minh chưa đủ. Sự khẳng định xuất hiện khi hội đủ cơ sở chứng minh. Sự khẳng định của VKSND - thể hiện qua bản cáo trạng và quyết định truy tố bị can - mới là thực hành quyền công tố. Nhận thức này đặt ra vấn đề phải sửa đổi các quy phạm pháp luật liên quan. Hiện nay, các quy định về vai trò của VKSND trong giải quyết nguồn tin về tội phạm nói chung, vai trò thực hành quyền công tố nói riêng được thể hiện trong BLTTHS 2015 và Luật Tổ chức Viện kiểm sát nhân dân 2014. Để bảo đảm sự nhất quán giữa các văn bản, cần sửa đổi đồng thời hai đạo luật nói trên. Trong phạm vi bài viết này, chúng tôi chỉ tập trung làm rõ quy phạm trong BLTTHS 2015, cụ thể là Điều 159 của Bộ luật.

Tiêu đề Điều 159 dễ dẫn đến nhận thức $\mathrm{Co}$ quan điều tra là chủ thể thực hành quyền công tố trên thực tế. Bởi lẽ, đa phần nội dung của điều luật này đều thể hiện vai trò của VKSND là đề ra các quyết định trong khi Cơ quan điều tra trực tiếp thi hành. Cụ thể, khoản 1: "Phê chuẩn, không phê chuẩn việc bắt người bị giũ trong truoòng hơp khẩn cấp, gia hạn tạm giũ; phê chuẩn, không phê chuẩn các biện pháp khác hạn chế quyền con người, quyền công dân..."; khoản 2: “...đề ra yêu cầu kiểm tra, xác minh và yêu cầu cơ quan có thẩm quyền giải quyết nguồn tin về tội phạm thực hiện...", khoản 3: "Quyết định gia hạn thời hạn giải quyết tố giác, tin báo về tội phạm, kiến nghị khởi tố..."; khoản 4: "Yêu cầu Co quan điè̀u tra, co" quan được giao nhiệm vu tiến hành một số hoạt động điều tra khởi tố vu án hình sụ"; khoản 6: "Hưy bỏ quyết định tạm giũu, quyết định khởi tố vu án hình sụ, quyết định không khởi tố vu án hình sụ, quyết định tạm đình chi giải quyết nguồn tin về tộ phạm và các quyết định tố tụng khác trái pháp luật của Co quan điều tra...". Đề ra và thực hiện là hai bước không thể tách rời để một quyết định có hiệu lực. Cả hai bước đều nhằm tới một hậu quả giống nhau. Do vậy, "đề $r a$ quyết định" mang tính chất nào thì "thực hiện quyết định" mang tính chất đó. Nếu việc "đề ra quyết định" của VKSND được coi là thực hành quyền công tố thì sự "thưc hiện quyết định" của Cơ quan điều tra cũng có ý nghĩa tương tự. Nói cách khác, từ các khoản 1, 2, 3, 4, 6 Điều 159 BLTTHS 2015, có thể suy luận Cơ quan điều tra cũng thực hành quyền công tố - điều này mâu thuẫn với phân tích về chủ thể quyền công tố đã nêu.

Điều 159 BLTTHS 2015 còn dẫn đến khó hiểu trong căn cứ phát sinh quyền công tố. Khoản 3 điều luật này có quy định VKSND "Quyết định khởi tố vụ án hình sụ". Dẫn chiếu đến khoản 3 Điều 153 BLTTHS 2015, VKSND ra quyết định khởi tố vụ án trong trường hợp "Viện kiểm sát hủy bỏ quyết định không khởi tố vu án hình sư của Co quan điều tra, co quan đuoơc giao nhiệm vu tiến hành một số hoạt động điều tra" (điểm a); "Viện kiểm sát trực tiếp giải quyết tố giác, tin báo về tội phạm, kiến nghị khởi tố" (điểm b). Mà quyền hạn ở điểm $\mathrm{b}$ ), khoản 3 Điều 153 được thực hiện khi VKSND “...phát hiện Co quan điều tra, co quan được giao nhiệm vu tiến hành một số hoạt động điều tra có vi pham pháp luật nghiêm trọng trong hoạt động kiểm tra, xác minh tố giác, tin báo về tội phạm, kiến nghị khởi tố hoặc có dấu hiệu bỏ lọt tội phạm mà Viện kiểm sát đã yêu cầu bằng văn bản nhung không được khắc phuc" (điểm c, khoản 3, Điều 145 BLTTHS 2015). Khoản 5, Điều 159 BLTTHS 2015 cũng dẫn chiếu đến điểm c, khoản 3, Điều 145 BLTTHS 2015. Như vậy, căn cứ để Viện kiểm sát nhân dân thực hành quyền công tố tại khoản 3 và khoản 5 Điều 159 BLTTHS 2015 là sai sót, vi phạm của 
cơ quan điều tra mà không phải là tội phạm được thực hiện.

Từ những phân tích nêu trên, có thể khẳng định tiêu đề Điều 159 BLTTHS 2015 làm sai lệch bản chất thẩm quyền của VKSND trong giải quyết tố giác, tin báo tội phạm và kiến nghị khởi tố. VKSND vẫn đóng vai trò quan trọng trong những hoạt động này, nhưng không nên hiểu là thực hành quyền công tố. Điều 159 cần được xóa bỏ khỏi BLTTHS 2015, các khoản trong điều này cần được bỏ hoặc quy định trong những điều luật khác phù hợp hơn.

Các khoản cần được bỏ bao gồm: khoản 7 , một phần các khoản 6,4 và 3 Điều 159 BLTTHS 2015. Khoản 7 Điều 159 BLTTHS quy định Viện kiểm sát: "Thực hiện nhiệm vu, quyền hạn khác trong việc thưc hành quyền công tố theo quy định của Bộ luật này nhằm chống bỏ lọt tội pham, chống làm oan nguời vô tội". Tương tự, một phần khoản 6 nêu rõ Viện kiểm sát được quyền hủy bỏ: “các quyết định tố tung khác trái pháp luật của Co quan điều tra, co quan được giao nhiệm vu tiến hành một số hoạt động điều tra". Ghi nhận "quyền hạn khác trong việc thực hành quyền công tố"; "các quyết định tố tụng khác" đồng nghĩa với việc khoản 6 và khoản 7 tồn tại dựa trên căn cứ thừa nhận VKND thực hành quyền công tố trong giải quyết nguồn tin về tội phạm. Vậy, bỏ Điều 159 BLTTHS 2015 sẽ đương nhiên bỏ khoản 7 và một phần khoản 6 điều luật này.

Nội dung khoản 3: "quyết định khởi tố vu án hình sư"; khoản 6: hủy bỏ "quyết định khởi tố vu án hình sự, quyết định không khởi tố vu án hình sự" trái pháp luật của cơ quan điều tra, cơ quan được giao nhiệm vụ tiến hành một số hoạt động điều tra và toàn bộ khoản 4: "Yêu cầu $C o$ " quan điều tra, co quan được giao nhiệm vu tiến hành môt số hoạt động điều tra khởi tố vu án hình sư" liên quan đến vai trò của VKSND trong việc khởi tố vụ án hình sự và đã được quy định trong những điều luật sau đó. Do vậy, khoản 4 , một phần khoản 3 và khoản 6 cũng cần được loại bỏ khi sửa đổi BLTTHS 2015.

Cuối cùng là các khoản nên được quy định ở những điều luật khác phù hợp hơn, bao gồm khoản 1: "Phê chuẩn, không phê chuẩn việc bắt nguoơi bi giữ trong trường hơp khẩn cấp, gia hạn tạm giữ; phê chuẩn, không phê chuẩn các biện pháp khác hạn chế quyền con người, quyền công dân trong việc giải quyết nguồn tin về tội phạm theo quy định của Bộ luật này"; khoản 2: "Khi cần thiết, đề ra yêu cầu kiểm tra, xác minh và yêu cầu cơ quan có thẩm quyền giải quyết nguồn tin về tội phạm thưc hiện"; khoản 3: "Quyết định gia hạn thời hạn giải quyết tố giác, tin báo về tội phạm, kiến nghi khởi tố"; khoản 5: "Trực tiếp giái quyết tố giác, tin báo về tộ phạm, kiến nghị khởi tố trong các trường hợp do Bộ luật này quy dịnh"; khoản 6: "Hủy bỏ quyết định tạm giữ, quyết định tạm đình chỉ giải quyết nguồn tin về tộ phạm và các quyết định tố tụng khác trái pháp luật của co quan điều tra, co quan tiến hành một số hoạt động điều tra". Những khoản này nên gộp vào Điều 160 BLTTHS 2015: "Nhiệm vu, quyền hạn của Viện kiểm sát trong việc tiếp nhận và kiểm sát việc giải quyết nguồn tin về tội phạm". Lý do cụ thể của kiến nghị này xin được trình bày tại phần 2 của bài viết.

\section{Chức năng kiểm sát việc tuân theo pháp luật trong giải quyết tố giác, tin báo tội phạm và kiến nghị khởi tố}

Kiểm sát việc tuân theo pháp luật trong giải quyết tố giác, tin báo tội phạm và kiến nghị khởi tố có vai trò vô cùng quan trọng. Bởi lẽ, giải quyết tố giác, tin báo tội phạm và kiến nghị khởi tố là bước đầu tiên trong toàn bộ tiến trình tố tụng hình sự. Hiệu quả thực hiện những công tác này sẽ quyết định chất lượng của toàn bộ hoạt động tố tụng về sau.

Về mặt lý luận, vấn đề thu hút sự quan tâm của các nhà khoa học hiện nay là loại bỏ hay duy trì chức năng kiểm sát của VKSND. Điều này đương nhiên bao hàm cả vai trò kiểm sát việc giải quyết tố giác, tin báo tội phạm và kiến nghị khởi tố. Giải quyết vấn đề này, chúng tôi tiến hành nghiên cứu so sánh các nền tài phán. Trên thế giới, mặc dù việc tổ chức quyền lực nhà nước trong giải quyết vụ án ở mỗi nước 
khác nhau, nhưng phần lớn, Viện Công tố đều có vai trò trong giải quyết nguồn tin về tội phạm. Ở Pháp, Viện công tố có trách nhiệm theo dõi, quản lý mọi thông tin về tội phạm và quyết định việc xử lý tố giác, tin báo về tội phạm. Các cơ quan, tổ chức khi tiếp nhận tố giác, tin báo về tội phạm phải thông báo cho Viện Công tố. Ở Đức, không có cơ quan điều tra riêng mà chính cơ quan công tố thực hiện nhiệm vụ này. Cơ quan công tố có trách nhiệm tiến hành điểu tra ngay khi nhận được tin báo, tố giác về tội phạm [2]. Ở các nước theo truyền thống thông luật, điều tra được coi là hoạt động của riêng cảnh sát, các cơ quan công tố chỉ tham gia vào hoạt động truy tố và buộc tội trước Tòa nên không thể hiện vai trò trong giải quyết nguồn tin về tội phạm. Nhưng theo thời gian, điều này đang dần thay đổi. Có ý kiến cho rằng: Nếu cơ quan công tố không kiểm sát việc điều tra thì cơ quan điều tra mới thực sự nắm quyền công tố [3]. Các so sánh giúp chúng ta đưa ra kết luận: vai trò kiểm tra, giám sát hoạt động của cơ quan điều tra nói chung, hoạt động tiếp nhận, giải quyết nguồn tin về tội phạm nói riêng nảy sinh từ yêu cầu khách quan, còn quan điểm đánh giá vai trò này phụ thuộc vào tổ chức cơ quan tố tụng từng nước.

Ở Việt Nam, trong xu hướng nghiên cứu chuyển đổi Viện kiểm sát thành Viện Công tố, một số ý kiến cho rằng nên bỏ chức năng kiểm sát với lý do: chỉ đạo, kiểm sát hoạt động điều tra (có người cho là điều tra) là một trong những nội dung của quyền công tố [4]. Dù không nhắc đến việc giải quyết tố giác, tin báo tội phạm và kiến nghị khởi tố nhưng luồng ý kiến này đã bao trùm mọi hoạt động trước truy tố. Thực chất, những quan điểm này chỉ phủ nhận sự kiểm sát với tư cách một chức năng riêng biệt chứ không phải giá trị thực tiễn của thẩm quyền đó. Theo chúng tôi, trong hoàn cảnh Việt Nam hiện nay, pháp luật tố tụng hình sự vẫn nên duy trì chức năng của VKSND kiểm sát việc tuân theo pháp luật nói chung, kiểm sát việc giải quyết tố giác, tin báo tội phạm và kiến nghị khởi tố nói riêng. Thứ nhất, theo những nhận thức về quyền công tố đã nêu, hoạt động giải quyết tố giác, tin báo tội phạm và kiến nghị khởi tố không phải nội dung của quyền công tố. Dù đổi mới tổ chức các cơ quan tiến hành tố tụng, bản chất của những hoạt động trên vẫn không thay đổi. Thứ hai, việc chuyển đổi VKSND trở thành Viện công tố, đồng thời VKSND chỉ đạo hoạt động giải quyết vụ án là một quá trình lâu dài, phức tạp, còn gặp phải nhiều vướng mắc. Mà chính việc tổ chức Viện công tố mới quyết định hoạt động kiểm sát việc tuân theo pháp luật không được coi là một chức năng riêng biệt. Ở những nước theo mô hình Viện công tố, hoặc không thành lập cơ quan điều tra, hoặc cơ quan điều tra chịu sự chỉ đạo của Viện Công tố ngay từ đầu. Hiện tại ở Việt Nam, cơ quan điều tra vẫn là một chủ thể riêng biệt, không chịu sự chỉ đạo của VKSND. Cuối cùng, hoạt động tiếp nhận, giải quyết tin báo, tố giác tội phạm và kiến nghị khởi tố là yếu tố "đầu vào" của toàn bộ quá trình tố tụng. Tính chính xác, chặt chẽ trong những hoạt động này liên quan mật thiết đến chất lượng truy tố bị can và buộc tội bị cáo về sau. Mặc dù cơ quan điều tra đóng vai trò chính trong tiếp nhận, giải quyết tin báo, tố giác tội phạm và kiến nghị khởi tố nhưng khi công nhận kết quả những hoạt động này thì VKSND cũng phải chịu trách nhiệm. Bởi vậy, cần thiết phải duy trì chức năng kiểm sát của VKSND để hạn chế tới mức thấp nhất sai sót của cơ quan điều tra.

Trong BLTTHS 2015, quy định về chức năng kiểm sát của VKSND trong việc giải quyết nguồn tin về tội phạm được xác định tại Điều 160: "Nhiệm vu, quyền hạn của Viện kiểm sát trong việc tiếp nhận và kiểm sát việc giải quyết nguồn tin về tọi phạm". Vì Điều 20 BLTTHS 2015: "Trách nhiệm thực hành quyền công tố và kiểm sát việc tuân theo pháp luật trong tố tụng hình sự" bao quát mọi dạng hoạt động kiểm sát nên sự kiểm sát việc giải quyết nguồn tin về tội phạm cũng là kiểm sát việc tuân theo pháp luật. Trong lý luận chung về nhà nước và pháp luật, "tuân theo pháp luật là một dạng thưc hiện pháp luật mang tính chất thu động, thể hiện ở việc các chủ thể phải kiềm chế bản thân để không thực hiện những hành vi mà pháp luật cấm. Nhũng quy phạm pháp luật cấm trong luật hình sư, luật hành chính được thể 
hiện dưới hình thức này" [5]. Theo TS Lê Lan Chi, nếu hiểu thuật ngữ tuân theo pháp luật theo quan điểm của lý luận chung thì nội hàm thuật ngữ "kiểm sát việc tuân theo pháp luật" sẽ bị thu hẹp đáng kể, việc "tuân theo pháp luật trong tố tụng hình sự" đã bao hàm tất cả các hình thức thực hiện pháp luật: áp dụng pháp luật, sử dụng pháp luật, thi hành pháp luật, tuân theo pháp luật [6]. Chúng tôi tán thành quan điểm này. Khi giải quyết tố giác, tin báo tội phạm và kiến nghị khởi tố, hoạt động của co quan điều tra hầu như mang tính chủ động. Vậy kiểm sát hoạt động của cơ quan điều tra phải được hiểu là kiểm sát mọi hình thức thực hiện pháp luật của cơ quan này. Thiết nghĩ, khi sửa đổi BLTTHS 2015, các quy định giải thích khái niệm "tuân theo pháp luâtt" và "kiểm sát việc tuân theo pháp luật" cần được bổ sung để tạo thống nhất trong nhận thức và áp dụng các quy phạm pháp luật.

Đối với quy định trong BLTTHS 2015 về chức năng kiểm sát việc giải quyết tố giác, tin báo tội phạm và kiến nghị khởi tố, khoản $1,2,3,5$ và 6 Điều 159 nên được gộp vào Điều 160 vì nội dung các khoản này cũng thể hiện tính chất kiểm sát. Kiểm sát bao gồm "kiểm tra và giám sát" [7]. Cũng như mọi sự giám sát khác, sự kiểm sát có những đặc trưng sau: (1) về chủ thể, phải có hai cá nhân, tổ chức riêng biệt trở lên: người kiểm sát và người bị kiểm sát. (2) Đối tượng của sự kiểm sát chính là các hoạt động của người bị kiểm sát, và (3) mục đích nhằm tránh hoặc giảm tối đa hậu quả các sai sót, vi phạm pháp luật trong hoạt động của người bị kiểm sát. TS Lê Lan Chi phân loại quyền kiểm sát thành hai nhóm: nhóm các quyền nhằm phát hiện việc vi phạm pháp luật và nhóm các quyền nhằm khắc phục xử lý vi phạm [8]. Nhóm các quyền nhằm phát hiện việc vi phạm pháp luật bao gồm: các quyền kiểm tra, giám sát hoạt động điều tra, hoạt động xét xử, hoạt động tạm giữ, tạm giam, quản lý vào giáo dục người chấp hành án phạt tù, hoạt động thi hành án hình sự. Nhóm các quyền nhằm khắc phục, xử lý vi phạm, bao gồm: quyền yêu cầu khắc phục các vi phạm; quyền yêu cầu xử lý nghiêm minh Điều tra viên và những người có thẩm quyền khác đã vi phạm pháp luật; quyền kiến nghị, kháng nghị nhằm khắc phục các nguyên nhân và điều kiện vi phạm pháp luật; quyền yêu cầu ra văn bản giải quyết khiếu nại, tố cáo; kiểm tra, trực tiếp kiểm sát việc giải quyết khiếu nại, tố cáo...Ngoài cách phân loại của TS Lê Lan Chi, các quyền kiểm sát có thể được chia thành hai nhóm như sau: nhóm quyền thứ nhất nhằm ngăn ngừa những vi phạm tiềm tàng của cơ quan tiến hành tố tụng; còn nhóm quyền thứ hai nhằm giải quyết hậu quả các vi phạm đã xảy ra. Cả hai nhóm đều thể hiện mục đích của sự kiểm sát: chống lại những sai sót, vi phạm của cơ quan công quyền.

Đối chiếu với các đặc điểm của sự kiểm sát, chúng ta thấy quy định tại khoản $1,2,3,5$ và 6 Điều 159 BLTTHS 2015 hoàn toàn mang tính chất kiểm sát việc tuân theo pháp luật. Các hoạt động này có sự xuất hiện của hai chủ thể là VKSND và cơ quan điều tra. Về nội dung của điều luật, vai trò của VKSND hoặc là "tư thực hiện", hoặc là "ra quyết định". Vai trò "đề ra quyết định" thể hiện ở khoản 1: "phê chuẩn, không phê chuẩn việc bắt người bi giũ trong truoòng hơp khẩn cấp...”; khoản 2: “...đề ra yêu cầu kiểm tra, xác minh và yêu cầu co quan có thẩm quyền giải quyết nguồn tin về tội phạm thưc hiện..."; khoản 3: "Quyết định gia hạn thời hạn giải quyết tố giác, tin báo về tội phạm, kiến nghị khởi tố"; khoản 6: "hủy bỏ quyết định tạm giữ, quyết định tạm đình chi giải quyết nguồn tin về tội phạm và các quyết định tố tụng khác trái pháp luật của Co quan điều tra, co quan đuợc giao nhiệm vu tiến hành một số hoạt động diều tra". Trong những hoạt động này, dù cơ quan điều tra mới là người trực tiếp thi hành nhưng sự đồng ý hoặc yêu cầu của VKSND là yếu tố bắt buộc để quyết định được thực hiện, đồng thời VKSND phải chịu trách nhiệm với các quyết định. Như vậy, đối tượng mà quyền lực VKSND tác động vào chính là hoạt động của cơ quan điều tra. Đồng thời, sự đồng ý hoặc đề xuất của VKSND có tác dụng phòng ngừa những sai phạm tiềm tàng trong giải quyết tin báo, tố giác tội phạm và kiến nghị khởi tố của cơ quan điều tra. Có thể xếp các khoản 1, 2, 3, 6 vào nhóm quyền thứ nhất: ngăn ngừa vi phạm 
pháp luật xảy ra. Vai trò "tụ thục hiện" được thể hiện tại khoản 5: "Trục tiếp giải quyết tố giác, tin báo về tọi phạm, kiến nghi khởi tố trong các truòng hợp do Bộ luật này quy định". VKSND thực hiện thẩm quyền này khi "phát hiện Co quan điều tra, co quan được giao nhiệm vu tiến hành một số hoạt động điều tra có vi pham pháp luât nghiêm trong trong hoat động kiểm tra, xác minh tố giác, tin báo về tội phạm, kiến nghi khởi tố hoạc có dấu hiệu bỏ lọt tội phạm mà Viện kiểm sát đã yêu cầu bằng văn bản nhưng không được khắc phục" (điểm c, khoản 3 Điều 145 BLTTHS 2015). Vậy, thẩm quyền tại khoản 5 được VKSND sử dụng nhằm giải quyết hậu quả của sự vi phạm mà cơ quan điều tra gây ra. Có thể xếp khoản 5 vào nhóm quyền thứ hai của sự kiểm sát: nhóm các quyền nhằm khắc phục, xử lý vi phạm.

\section{Kết luận}

So với BLTTHS 2003, BLTTHS 2015 đã có những thay đổi đáng kể mà quy định về chức năng công tố, chức năng kiểm sát việc tuân theo pháp luật của VKSND trong giải quyết tố giác, tin báo tội phạm, kiến nghị khởi tố là điểm mới nổi bật. Tuy nhiên, các quy định mới chưa thực sự thuyết phục về mặt lý luận. Qua phân tích, nhóm tác giả đưa ra một số quan điểm về chức năng công tố cũng như chức năng kiểm sát việc tuân theo pháp luật của VKSND. Trên cơ sở đó, đề xuất bỏ quy định về thực hành quyền công tố, bổ sung quy định kiểm sát việc tuân theo pháp luật trong giải quyết tố giác, tin báo tội phạm, kiến nghị khởi tố. Những vấn đề được nêu ra trong bài viết cần tiếp tục nghiên cứu, đánh giá để tạo sự thống nhất về nhận thức của những người có thẩm quyền và kịp thời sửa đổi, bổ sung trong BLTTHS 2015 trước khi Bộ luật chính thức có hiệu lực./.

\section{Tài liệu tham khảo}

[1] Từ điển luật học, Nxb Từ điển Bách khoa 1999.

[2] Nguyễn Đăng Dung (chủ biên), Viện kiểm sát nhân dân trong Nhà nước pháp quyền, $\mathrm{Nxb}$ Tư pháp, Hà Nội, 2014, tr.103.

[3] inter alia Lidstone, K., "The Reformed Prosecution Process in England: A Radical Reform?” (1987) Criminal Law Journal, p. 296 and Fionda, J., "Public Prosecutors and Discretion: A Comparative Study", Oxford, Clarendon Press, 1995.

[4] Nguyễn Ngọc Chí, Quy định về Viện kiểm sát nhân dân trong Hiến pháp 1992: Một vài đề xuất sửa đổi, Hiến pháp: Những vấn đề lý luận và thực tiễn, Nxb. Đại học Quốc gia Hà Nội, 2011, tr. 932, 933. Trần Văn Độ, Một số vấn đề về quyền công tố, Tạp chí Luật học số 3/2001, tr.12.

[5] Trường Đại học Luật Hà Nội (2003), Giáo trình lý luận Nhà nước và pháp luật, $\mathrm{Nxb}$ Chính trị quốc gia, tr.463, 464.

[6] Lê Lan Chi, Kiểm sát việc tuân theo pháp luật trong tố tụng hình sự - một số vấn đề lý luận và thực tiễn, luận văn thạc sỹ luật học, Hà Nội, năm 2005, tr. 18 .

[7] Hoàng Phê (chủ biên), Từ điển Tiếng Việt, Nxb Từ điển Bách khoa, 2012.

[8] Lê Lan Chi, Phân biệt khái niệm "kiểm sát việc tuân theo pháp luật trong tố tụng hình sự" với các khái niệm liền kề, Tạp chí Nghề luật, số 5/2007. 


\title{
The Functions of People's Procuracy in the Processing of Denunciations, Criminal Information Disclosed, Requisitions for Charges according to Criminal Procedure Code 2015 and some Suggestions for Improvement
}

\author{
Tran Thu Hanh, Ngo Long Khanh \\ VNU School of Law, 144 Xuan Thuy, Cau Giay, Hanoi, Vietnam
}

\begin{abstract}
In the context that the promulgated Criminal Procedure Code (CrPC) 2015 has not yet come into effect, the paper studies some provisions on the functions of the People's Procuracy in the processing of denunciations, criminal information disclosed, requisitions for charges and proposes recommendations to improve these provisions in Criminal Procedure Code 2015.
\end{abstract}

Keywords: The right of prosecution, overseeing legal compliance, the processing of denunciations, criminal information disclosed and requisitions for charges, Criminal Procedure Code 2015. 